\title{
PENGARUH KOMPENSASI, KECERDASAN SPIRITUAL, GENDER DAN USIA TERHADAP KOMITMEN ORGANISASI DOSEN TEKNIK INDUSTRI X DI TANGSEL
}

\author{
${ }^{1)}$ Khairunnisa, ${ }^{1)}$ Sri Uami Ningsih \\ Dosen Prodi Teknik Industri, Fakultas Teknik, Universitas Pamulang, Tangerang Selatan, Banten \\ dosen00743@unpam.ac.id, dosen00456@unpam.ac.id
}

\begin{abstract}
ABSTRAK
SDM (Dosen) yang berkualitas memerlukan keterlibatan yang tinggi terhadap pekerjaaan atau organisasi yang disebut sebagai komitmen organisasi. Berdasarkan penelitian terdahulu oleh faktor imbalan dan faktor personal mempengaruhi komitmen organisasi dosen. Pada penelitian ini, penulis ingin melihat sumbangan proporsi varian yang dijelaskan oleh kompensasi, faktor personal dalam bentuk kecerdasan spiritual individu, jenis kelamin dan usia yang dapat memberikan pengaruh terhadap komitmen organisasi dosen. Responden pada penelitian ini hanya dapat diperoleh 30 dosen Teknik Industri X, dengan Jenis penelitian Deskriptif statistic. Hasil dari penelitian ini adalah kompensasi memiliki signifikasi $0,000<0,05$ dengan kenaikan 0,719 berpengaruh pada komitmen organisasi, kecerdasan spiritual memiliki signifikansi $0.007<0,05$ dengan kenaikan 0,13 berpengaruh pada komitmen Organisasi. Usia memiliki nilai 0,95>0,05 yang menunjukkan tidak signifikannya variabel tersebut meskipun memiliki koefisien 3,155 lebih besar proporsinya dari variabel lain dalam mempengaruhi komitmen organisasi. Lalu gender memiliki nilai $0,124>0,05$ yang menunjukkan tidak signifikannya variabel tersebut dengan koefisien regresi yang rendah $(-3,014)$ atau tidak berpengaruh terhadap komitmen organisasi. Namun jika diuji secara simultan variabel kompensasi, spiritual quetiont, gender dan usia secara bersama-sama berpengaruh sebesar 86,5\% terhadap komitmen organisasi dosen.
\end{abstract}

Kata Kunci: Kompensasi, keserdasan spiritual, Usia, Gender dan Komitmen Organisasi.

\section{PENDAHULUAN}

Mutu pendidikan dari pendidikan Tinggi ditunjang oleh Sumber Daya Manusia (SDM) nya. Tenaga pengajar yang memiliki kualitas tinggi dapat memeberikan sumbangan kepada institusi dan juga mahasiswanya. Keterkaitan hubungan antara tenaga pengaar dengan isntatsi satuan kerja meruaka hala yang yang perlu diperhatikan dalam hal ini hubungan yang baiak sangatlah diharpkan Hal ini erat dengan komitmen organisasi yang tinggi dengan tujuan memilih antau mengedepankan instatsi tempat seorang melakukan perekrutan. Jenifer dan Gareth (2002). Namun keinginan kuat seseorang terhadap instatasi ataupun organisnya tidak lahir tanpa sebab, semua memerlukan proses dan penelitian lebih lanjut. Penelitian Sodang (dalam Kuncoro \&
Ridwan, 2008) mencoba mengidentifikasi faktor pekerjaan pada organisasi pendidikan, menunjukkan pandangan tentang pemberian honor atau tunjangan lain, diberikan fasilitas kerja juga termasuk padanya lingkungankondisi yang nyama dan aman kepada dosen, ternyata memberikan konstribusi 61,68 persen pada motivasi kerja dosen sehingga memiliki komitmen dalam menjalankan tugasnya di perguruan tinggi. Penelitian lain di luar dari organisasi pendidikan, menegaskan bahwa imbalan atau honor juga masih merupakan isu penting yang menarik atau yang dapat mempertahankan karyawan dalam organisasi. Sebagaimana terungkap dalam Towers Watson Global Workforce Study 2012 (TW - GWS, 2012) yang melibatkan lebih dari 32,000 karyawan yang dipilih.(www.portalhr.com, diunduh 27/09/12). 
Berdasarkan Penelitian tersebut menunjukkan bahwa faktor gaji atau kompensasi dapat menjadi alasan utama seseorang bertahan dalam organisasi dengan komitmen yang melekat pada diri individu. Selanjutnya, faktor personal yang membuat seseorang dapat bertahan dalam organisasi juga memberikan perhatian tersendiri. Hal ini erat kaitannya dengan tanggung jawab moral yang tercermin sebagai kematangan spiritualitas.

Kecerdasan spiritual (SQ) adalah kecerdasan jiwa, Kecerdasan spiritual merupakan kecerdasan yang ada dibagian seseorang yang berhubungan dengan kearifan di luar ego atau pikiran sadar. Kecerdasan spiritual memberikan manusia kemampuan membedakan, memberikan rasa moral, menyesuaikan kemampuan yang kaku dibarengi dengan pemahaman. Kecerdasan spiritual (Spiritual Quotient) memfasilitasi dialog antara akal dan emosi, antara pikiran dan tubuh. Kecerdasan spiritual menyediakan pusat pemberi makna yang aktif dan menyatu bagi diri kita. Kecerdasan spiritual (Spiritual Quotient) menjadikan manusia makhluk yang betul betul seutunya baik itu karakteristik emosional intelektual ataupun spritualnya..

Dalam penelitian ini, penulis akan mengaitkan faktor Kompensasi dan Spiritual Quotien sebagai variabel prediktor yang diasumsikan dapat mempengaruhi komitmen dosen terhadap organisasi. Oleh karena itu, penulis ingin menelaah bagaimana sumbangan / pengaruh Kompensasi dan Spiritual Quotien terhadap komitmen organisasi dengan subjek penelitian dosen yang berada di Teknik Industri X di Tangsel.

\section{DASAR TEORI}

\section{A. Komitmen Organisasi}

Dasar ketentuan yang di anut oleh suatu rganisasi sudah menembuaty daya Tarik yang agak lumayan besar pada apa yang akan dipahami serat menjelaskan kesetabilan dan instensiatas suatu organsasi (Lumley, 2010). Komitmen menjelaskan mengenai dimenstion organization pada keterangan dibawah ini :

"Affective commitment refers to the employees emotional attachment to, identification with, and involvement in the organization. Employees with a strong affective commitment continue employment with an organization because they want to do so. Continuance commitment refers to an awareness of the costs associated with leaving the organization. Employees whose primary link to the organization is based on continuance commitment remain because they need to do so. Finally, normative commitment reflects a feeling of obligation to continue employment. Employees with a high level of normative commitment feel that they ought to remain with the organization." (p. 167).

Penjelasan menunjukkan bahwa komitmen organisasi terbentuk dari tiga komponen komitmen yang saling mengikat dan berhubungan.

\section{B. Kompensasi}

Rivai mengatakan: "Kompensasi merupakan sesuatu yang diterima karyawan sebagai pengganti kontribusi jasa mereka pada perusahaan. Pemberian kompensasi merupakan salah satu pelaksanaan fungsi MSDM yang berhubungan dengan semua jenis pemberian penghargaan individual sebagai pertukaran dalam melakukan tugas keorganisasian."

\section{Kecrdasan Spiritual (Spiritual Quetiont)}

Kecerdasaa spiritual ini ialah suatu kecerdasan dalam menangani maslah ketentuan nilai dan makna, yang diataranya agar memposisikan prilaku atau gaya hidup dalam pengertian arti yang lebih secara luas. Kecerdasan dalam menilai Ketika ada tindakan atauun jalan kehidupan seorang lebih berarti dibandikan dengan kehidupan orang lain. (Zohar, 2001).

\section{Kerangka Berpikir}

Berikut ini model penelitian yang ingin penulis ketahui proporsi pengaruhnya : 


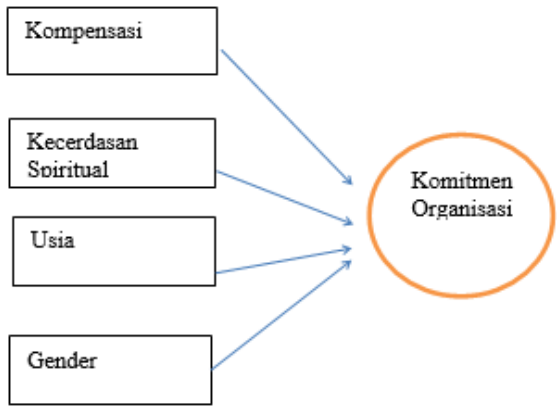

Gambar 1

Model Penelitian Komitmen Organisasi Penulis mengemukakan hipotesis dalam penelitian ini adalah: (1) terdapat pengaruh yang signifikan dari Kompensasi terhadap komitmen organisasi, (2) terdapat pengaruh yang signifikan dari Kecerdasan Spiritual terhadap komitmen organisasi, (3) terdapat pengaruh yang signifikan dari Usia terhadap komitmen organisasi, (4) terdapat pengaruh yang signifikan dari gender terhadap komitmen organisasi. (5) terdapat pengaruh secara simultan kompensasi, kecerdasan spiritual, usia, gender terhadap komitmen organisasi.

\section{METODE DAN TEKNIK PENGUKURAN}

\section{A. Jenis Penelitian}

Jenis penelitian yang digunakan dalam penelitian ini adalah Jenis penelitian survei yang berusaha mengambil keputusan dengan menggunakan data di lapangan atau dengan menggunakan daftar penyataan (kuesioner) yang kemudian dianalisa.. Variable yang di teliti sebanyak 3 variabel yaitu kompensasi, kecerdasan spiritual (spirituan Quetiont) dan Komitmen Organisasi.

\section{B. Populasi dan Sampel}

1) Populasi

2) sampel

\section{Data Penelitian}

Data penelitian yang dilambil oleh peneliti dengan menyebar kuesioner di prodi Teknik Industri Universitas atau Institusi X di Tangsel :sebagai berikut:

1) Skala Kompensasi

2) Skala Kecerdasan Spiritual (Spiritual Quetiont) la Kompensasi

\section{Teknik Pengumpulan Data}

Tknik pengumpulan data yang di lakukan dalam penelitian ini terdiri atas:

1) Observasi

Teknik pengumpulan data dengan cara turun langsung kelapangan dengan tujuan mendapatkan data aktual yang di perlukan dalam penelitian ini.

2) Kuesioner

Dilakukan secara tidak langsung melalui equesionnare yang disebar dengan link dengan dibatasi pada dosen-dosen Teknik Industri X

\section{E. Teknik Analisis Data}

Teknik yang digunakan yaitu analisa regresi berganda, penulis akan menguji signifikansi dari hasil yang didapat. Penulis akan menghitung proporsi varian dari komitmen organisasi yang dapat dijelaskan oleh variabelvariabel independen yang penulis teliti, yaitu R2. Jadi, penulis dapat mengetahui apakah regresi dari komitmen organisasi atas empat variabel independen signifikan secara statistik atau tidak. R2 diuji signifikannya secara simultan dengan uji F secara simultan. Langkah selanjutany adalah menguji regresi dengan setiap variable indepepnden. Koofisien regresi akan diuji oleh uji t yang dilaksankan agar mengetahui apa variable defenden ( $\mathrm{Y}$ )dengan variable independen (X) saling berpengaruh satu sama liannya.

\section{HASIL DAN PEMBAHASAN}

\section{A. Uji Model Regresi}

Untuk mengetahui hasil regresi linier maka harus mengethaui uji uji berikut yaitu, ujui $\mathrm{T}$ uji $\mathrm{R}$ uji $\mathrm{F} \mathrm{R}$ square dan mlain lain maka dari itu akan disampaikan berikut hasi uji uji untuk melihat hubungan antra variable.

Pada Analisa regresi linier berganda maka di gunakan uji t untuk menguji pengaruh parsial. Berikyt data table uji $\mathrm{t}$

Tabel 4.1 Hasil Uji Parsial

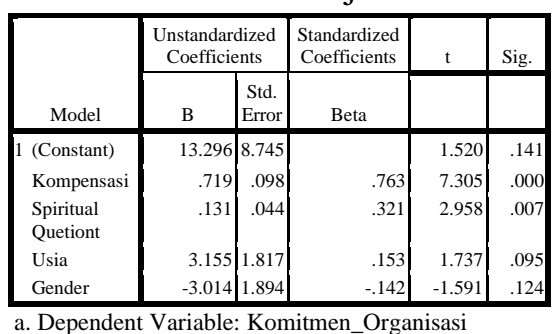


Dari hasil uji t di atas dapat dijelaskan sebagai berikut : 4.1 beberapa hasil sebagai berikut :

1) Nilai signifikan pengaruh variabel kompensasi terhadap komitmen organisasi sialah dengan besaran 0,000 dengan koefisien regresi bertanda positif. Oleh karena nilai signifikan yang diperoleh $<0,05$ dan koefisien regresi bertanda positif, disimpulkan bahwa kompemsasi berpengaruh positif dan signifikan terhadap komitmen organisasi, hal ini menunjukkan bahwa semakin baik pemberian kompensasi kepada dosen maka semakin tinggi komitmen dosen.

2) Nilai signifikan pengaruh variabel spiritual quetiont terhadap komitmen organisasi adalah sebesar 0,007 dengan koefisien regresi bertanda positif. Oleh karena nilai signifikan yang diperoleh < 0,05 dan koefisien regresi bertanda positif maka Ho ditolak dan disimpulkan bahwa spiritual quetiont berpengaruh positif dan signifikan terhadap komitmen organisasi, hal ini menunjukkan bahwa semakin tinggi spiritual quetiont dosen maka semakin tinggi komitmen organisasi dosen.

3) Nilai signifikan pengaruh variabel usia terhadap komitmen organisasi adalah sebesar 0,095. Oleh karena nilai signifikan yang diperoleh $>0,05$ maka disimpulkan bahwa usia tidak signifikan terhadap komitmen organisasi, hal ini menunjukkan bahwa usia dosen bukan merupakan faktor yang menentukan tinggi rendahnya komitmen organisasi dosen

4) Nilai signifikan pengaruh variabel gender terhadap komitmen organisasi adalah sebesar 0,124 . Oleh karena nilai signifikan yang diperoleh > 0,05 maka disimpulkan bahwa gender tidak berpengaruh terhadap komitmen organisasi, hal ini menunjukkan bahwa jenis kelamin bukan merupakan faktor yang menentukan tinggi rendahnya komitmen organisasi dosen

\section{b.Persamaan Regresi}

Berdasarkan hasil analisis regresi pada tabel 4.1, diperoleh nilai konstanta regersi sebesar 13,296, koefisien regresi variabel kompensasi sebesar 0,719, koefisien regresi variabel spiritual quetiont sebesar 0,131 , koefisien regresi variabel usia sebesar 3,155 dan koefisien regresi variabel gender sebesar -3,014. Berdasarkan nilai-nilai tersebut maka diperoleh persamaan regresi antara seluruh variabel bebas terhadap nilai perusahaan sebagai berikut :

$\mathrm{Y}=13,296+0,719 \mathrm{X} 1+0,131 \mathrm{X} 2{ }_{-} 3,155$

X3 - 3,014 X4

Dengan :

$\mathrm{Y}=$ komitmen organisasi

$\mathrm{X} 1=$ kompensasi

$\mathrm{X} 2=$ spiritual quetiont

$\mathrm{X} 3$ = usia

$\mathrm{X} 4$ = gender

Artinya, kompensasi memiliki signifikasi kenaikan 0,719 pada komitmen organisasi, kecerdasan spiritual memiliki kenaikan 0,13 pada komitmen Organisasi. Usia menunjukkan tidak signifikannya variabel tersebut meskipun memiliki koefisien 3,155 lebih besar proporsinya dalam mempengaruhi komitmen organisasi. Ini terjadi karena variasi usia dosen rata-rata dengan rentang sama dari 30-40 tahun sehingga penyebaran Usia yang tidak bervariasi dapat menjadi faktor berpengaruh atau tidaknya variabel tersebut pada komitmen organisasi. Lalu gender memiliki nilai $0,124>0,05$ yang menunjukkan tidak signifikannya variabel tersebut dengan koefisien regresi yang rendah $(-3,014)$. Artinya gender bukan merupakan faktor yang dapat mempengaruhi komitmen organisasi dosen

\section{c. $\quad$ Uji Simultan (Uji F)}

Dalam pengujian ini, ingin mengetahui proporsi varian empat variabel (kompensasi, kecerdasan spiritual, usia dan intelegensi) secara bersama-sama dalam mempengaruhi komitmen Organisasi sebagaimana yang dapat dijelaskan oleh tabel 4.2

Tabel 4.2 Hasil Uji Simultan

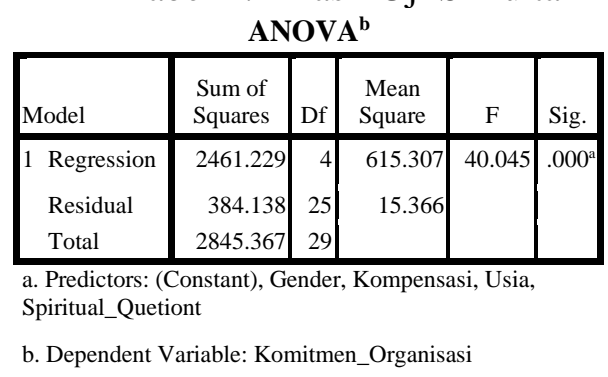

Berdsarkan hasil analisa regresi dari table di atas, diperoleh nilai signifikan hasil uji $\mathrm{F}$ sebesar 0,000. Oleh karena nilai signifikan 
hasil uji simultan $<0,05$. Artinya secara simultan kompensasi, spiritual quetiont, usia dan gender dosen berpengaruh terhadap komitmen organisasinya.

\section{d. Koefisien Determinasi}

pada Analisa regresiai liniear dan berganda koefisien determinan memperlihatkan besaranya pengaruh simultan varabel ndependen kepada variable defenden Adapun nilai tersbut dapat dilihat pada nila $\mathrm{R}$ square diabwah ini

Tabel 4.3 Kofisien Deteminasi Model Summary $^{\mathrm{b}}$

\begin{tabular}{|l|r|r|r|c|}
\hline $\begin{array}{l}\text { Mode } \\
1\end{array}$ & $\mathrm{R}$ & $\begin{array}{c}\mathrm{R} \\
\text { Square }\end{array}$ & $\begin{array}{r}\text { Adjusted } \\
\mathrm{R} \text { Square }\end{array}$ & $\begin{array}{c}\text { Std. Error of the } \\
\text { Estimate }\end{array}$ \\
\hline 1 & .930 & .865 & .843 & 3.91989 \\
\hline
\end{tabular}

a. Predictors: (Constant), Gender, Kompensasi, Usia, Spiritual_Quetiont

b. Dependent Variable: Komitmen_Organisasi Hasil analisis regresi pada tabel di atas menunjukkan bahwa nilai $\mathrm{R}$ Square model regresi adalah sebesar 0,865. Hal ini menunjukkan bahwa kompensasi, spiritual quetiont, gender dan usia secara bersamasama berpengaruh terhadap komitmen organisasi dengan besar kontribusi sebesar $86,5 \%$, sedangkan sisanya sebesar $13,5 \%$ variansi komitmen organisasi dosen dipengaruhi oleh faktor lain di luar kompensasi, spiritual quetiont, gender dan usia dosen.

\section{Pengujian Hipotesis}

a. Hipotesis 1

Untuk hasil uji hipotesis 1 maka didapatkan nilainya yang secara signifikan antara variable pengaruh kompensai kepada pengaruh variable komitmen yaitu sesesar 0,0000 adapun regresianya positif, maka dari itu dikarenakan nilai siginfikannya yang didapatkan $<0,05$ dan juga koefisiennya regresi dengan tanda positif maka dapat diartikan bahwa variable kompensasi berpengruh signifikan dan positif terhadap variable komitmen. organisasi, dapat diuraiakan mengenai haltersebut berarti jika makin tinggi kompensasi yang diberikan maka akan berpengaruh komitmen yang tinggi pula.

b. Hipotesis 2
Didapatkan nilai yang signifikan yaitu variable SQ kepada komitmen organissi dengan nilai 0,000 koefisien regresi bertanda psitif juga, maka dari itu dikarenakan nilai signifikan yang didapatkan < 0,05 dan koefisien dan Memiliki tanda positif dapat diartikan pengertiannya bahwa spiritual question memiliki pengaruh postih yang terhadap komitmen organisasi, hal ini menunjukkan bahwa semakin tinggi spiritual quetiont dosen maka semakin tinggi komitmen organisasi dosen.

2) Hipotesis 3

Nilai signifikan pengaruh variabel usia terhadap komitmen organisasi adalah sebesar 0,095. Oleh karena nilai signifikan yang diperoleh $>0,05$. Artinya, bahwa usia tidak berpengaruh terhadap komitmen organisasi, hal ini menunjukkan bahwa usia dosen bukan merupakan faktor yang menentukan tinggi rendahnya komitmen organisasi dosen.

3) Hipotesis 4

Nilai yang cukup siginifikan pengaruh variable usia kepada komitmen oragnisasi ialah senilai 0,0095 Oleh karena nilai signifikan yang diperoleh > 0,05 . Artinya, bahwa gender tidak komitmen organisasi dosen

4) Hipotesis 5

Secara bersama-sama variabel kompensasi, kecerdasan spiritual, gender, dan usia berpengaruh signifikan positif pada komitmen organisasi

\section{KESIMPULAN}

Berdasarkan hasil Analisa data dalam pembahasan maka dapat dia mbil kesimpulan sebagai berikut :

1. Kompensasi yang diperoleh dosen Teknik Industri $\mathrm{X}$ memiliki pengaruh positif dan signifikan terhadap komitmen organisasinya, semakin baik pemberian kompensasi yang diperoleh dosen Teknik Industri X maka semakin tinggi komitmen organisasi mereka terhadap intansi tempat bekerja.

2. Spiritual Quetiont yang diperoleh dosen Teknik Industri X memiliki pengaruh positif dan signifikan terhadap komitmen organisasinya, semakin tinggi kecerdasan emosional dosen Universitas di Tangerang 
Selatan maka semakin tinggi komitmen organisasi mereka terhadap intansi tempat bekerja.

3. Gender tidak memiliki pengruh positif dan signifikan terhadap komitmen organisasi dosen Teknik Industri $X$, jenis kelamin dosen bukan merupakan faktor yang berpengaruh terhadap tinggi rendahnya komitmen organisasi dosen.

4. Usia tidak berpengaruh positif dan signifikan terhadap komitmen organisasi dosen Teknik Industri $\mathrm{X}$ di Tangerang Selatan, usia dosen bukan merupakan faktor yang berpengaruh terhadap tinggi rendahnya komitmen organisasi dosen.

\section{DAFTAR PUSTAKA}

Bernardin H. John \& Joyce F. A. Russel. (2010). Human Resources Management an Experimental Approach. Singapore. McGraw Hill, Inc.

, (2010). Human Resource Management An Experiential Approach. New York. McGraw Hill.

Luthans, Fred, 2011, Perilaku Organisasi, Edisi Bahasa Indonesia, Penerjemah

Vivin A, Shekar Purwanti, dan Winong Rosari, Penerbit Andi, Yogyakarta.

Mathis, L. Robert dan Jackson, H. John, 2010, Manajemen Sumber Daya Manusia, Salemba Empat, Jakarta.

Nitisemito, Alex. S., 2009, Manejemen Personalia, Ghalia Indonesia, Jakarta.

Riduwan dan Engkos, 2011, Cara menggunakan dan Memaknai Path Analysis. Alfabeta, Bandung.

Robbins, S.P and Judge, 2013, Perilaku Organisasi, Salemba Empat, Jakarta , 2008, Perilaku Organisasi, Edisi 12, Prentice Hall, Djakarta 